\title{
Amiloidose laríngea primária: revisão bibliográfica e um caso relatado
}

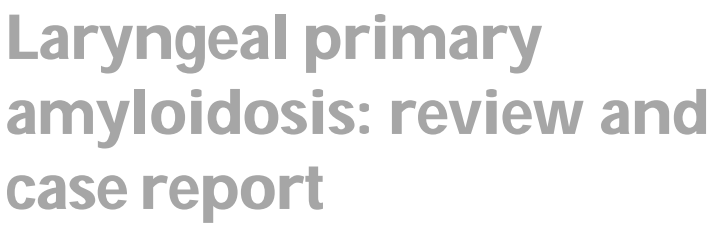

\author{
Amanda S. Bastos ${ }^{1}$, André Valente', \\ Daniel Buarque', Katianne Wanderley²
}

Palavras-chave: amiloidose, laringe, doença. Key words: amyloidosis, larynx, disease.

\section{Resumo / Summary}

aracterizada pelos depósitos extracelulares de uma substância de natureza proteica, desconhece-se ainda a real causa da amiloidose. Esta doença pode acometer qualquer parte do corpo, mas raramente aparece nas vias aéreas superiores; contudo, a laringe é o local mais comumente atingido por esses depósitos a este nível. Uma pequena revisão na literatura foi feita para investigar os aspectos clínicos, diagnóstico e opções terapêuticas disponíveis, possibilitando assim uma melhor conduta diante de um paciente com amiloidose laríngea. Os autores ressaltam a importância de se estar atento para o seu diagnóstico, uma vez que a doença, quando localizada, apresenta um prognóstico melhor. Neste estudo é apresentado um caso de amiloidose laríngea em um homem de 64 anos. haracterized by extracelular deposition of amyloid proteins, it's still unknown the real cause of amyloidosis. This illness can occur in any part of the body, but it rarely appears in the upper airway; however, the larynx is the most common local undertaken for these deposits in this level. A small review in the literature was made to investigate the clinical aspects, the diagnosis and the therapeutical options available, making possible a better behavior in a patient with laryngeal amyloidosis. The authors emphasize the importance of being attentive for the diagnosis, because when the disease is localized, the prognosis is better. In this study, it's presented a case of laryngeal primary amyloidosis in a 64-year-old man.

${ }^{1}$ Médico(a) O torrinolaringologista do Serviço de O torrinolaringologia da Santa Casa de Misericórdia de Maceió

${ }^{2}$ Residência e mestrado no Hospital das Clínicas da Faculdade de Medicina de Riberão Preto - USP; médica otorrinolaringologista do Serviço de O torrinolaringologia da Santa Casa de Misericódia de Maceió. Serviço de O torrinolaringologia da Santa Casa de Misericórdia de Maceió Endereço para Correspondência: R. Silvério Jorge, 474, Jaraguá 57020-710 Maceió AL Tel/Fax: (0xx82) 221-7009/ 221-7068/ 9981-5436 - E-mail: alessbt@uol.com.br 


\section{INTRODUÇÃO}

A amiloidose corresponde ainda a uma doença de etiologia desconhecida, caracterizada pela deposição extracelular de uma substância amorfa de natureza protéica, que tende a formar fibrilas. Foi primeiramente descrita por Rokitasnsky em 1842, mas o termo amiloidose foi designado por Virchow em 1851, para descrever a coloração avermelhada obtida pela reação do amilóide com o iodo. No entanto, o primeiro caso relatado de amiloidose só surgiu em 1875². Esses depósitos podem ocorrer em qualquer órgão, e ao nível da cabeça e pescoço, a laringe é o principal local acometido.

A amiloidose laríngea é uma doença incomum, correspondendo a menos de $1 \%$ de todas as lesões benignas da laringe. A sintomatologia não é específica, e dependerá do local da lesão. Assim, a rouquidão resulta do envolvimento das pregas vocais; depósitos subglóticos levam a dificuldades respiratórias; e lesão supraglótica gera precocemente disfagia ${ }^{1}$. 0 diagnóstico está na dependência da suspeita clínica, uma vez que os sintomas apresentados pelo paciente e 0 aspecto da lesão não são característicos. A vídeolaringoscopia pode mostrar lesões de aspectos variados, geralmente limitada, e de coloração avermelhada, onde a mucosa não ulcera e nem sangra ao contato. A laringe apresenta em geral boa mobilidade, embora infiltração importante possa levar a uma paresia. 0 estudo histopatológico do material biopsiado confirma o diagnóstico. A coloração com hematoxilina-eosina mostra uma substância homogênea de difícil distinção com outras substâncias hialinas. 0 teste com o vermelho de Congo é o mais comumente usado para confirmar o diagnóstico, o qual ao entrar em contato com o amilóide produz uma birrefringência esverdeada típica, quando em $\mathrm{pH}$ adequado ${ }^{1-5}$. Pela microscopia eletrônica é possível visualizar a estrutura fibrilar amilóidea 5 .

A doença faz diagnóstico diferencial com o pólipo da prega vocal, cistos de retenção das falsas cordas vocais, laringocele, tumores benignos e malignos da laringe incluindo o carcinoma de células escamosa invasivo ${ }^{1}$. laríngea.

A seguir, será apresentado um caso de amiloidose

\section{APRESENTACCÃO DE CASO CLÍNICO}

Um homem de 64 anos, negro, chegou ao Serviço de O torrinolaringologia da Santa Casa de Misericórdia de Maceió, em agosto de 1999, queixando-se de rouquidão há cerca de 1 ano acompanhada de sensação de aperto na garganta. Não apresentava dispnéia, disfagia ou perda de peso. Não tinha queixas nasais nem otológicas. Negava história de tabagismo e etilismo. A vídeolaringoscopia revelou espessamento circunscrito de coloração avermelhada no bordo livre da prega vocal esquerda, sugestivo de nódulo hemorrágico. Apresentava ainda edema da prega vocal direita, cavalgamento da aritenóide direita sobre a esquerda e fenda glótica em ampulheta devido à lesão.

0 paciente foi encaminhado para um tratamento fonoaudiológico, o qual realizou durante 3 meses sem obter melhora. Uma segunda videolaringoscopia foi realizada, e evidenciou um aumento da lesão, apresentando aspecto polipóide (Figura 1 - Foto maior). Em janeiro de 2000, sofreu intervenção cirúrgica para exérese da lesão sob microlaringoscopia direta (Figura 1 - Foto menor). 0 exame histopatológico com hematoxilina-eosina mostrou depósito de material amorfo, hialino, e por haver a suspeita de amiloidose laríngea, foi realizado o teste com o vermelho

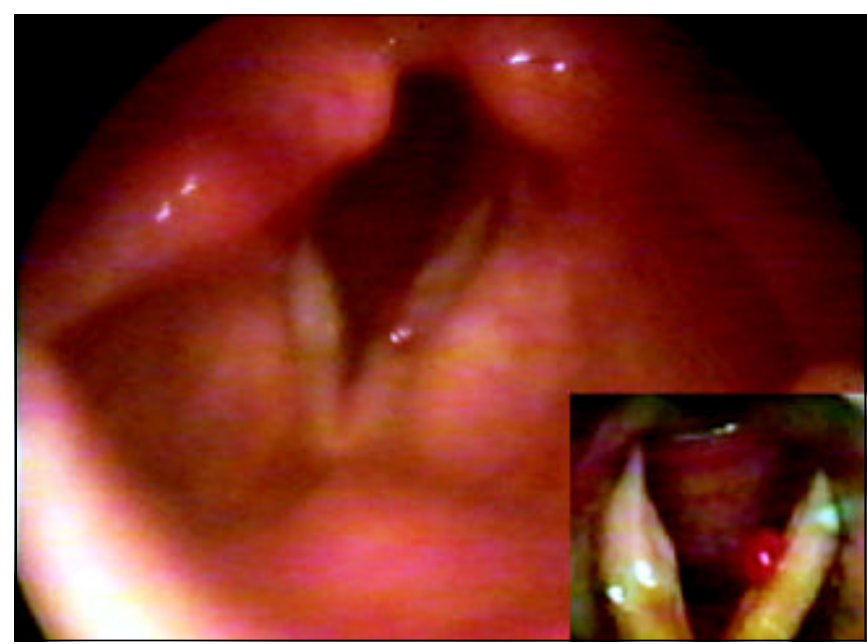

Foto 1. Foto maior: Imagem da 2 a videolaringoscopia: lesão de aspecto polipóide em prega vocal esquerda.

Foto menor: Imagem da microlaringoscopia durante 0 ato cirúrgico, evidenciando a lesão.

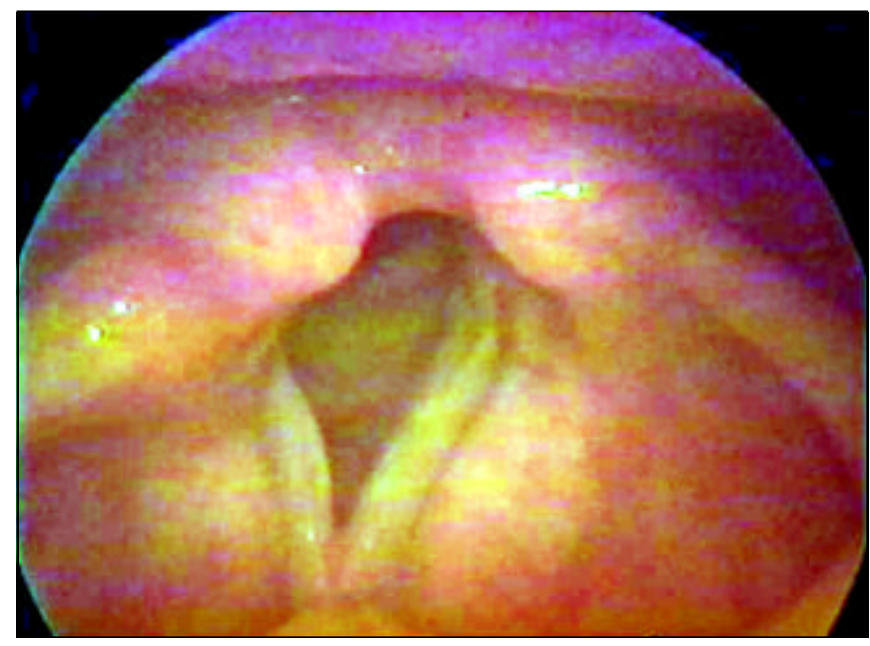

Foto 2. Imagem videolaringoscópica: pós-operatório tardio. 
de congo, onde se observou a birrefringência esverdeada sob luz polarizada, confirmando o diagnóstico.

O paciente foi então submetido a uma avaliação clínica geral para afastar doença secundária e/ ou sistêmica. Foram realizados hemograma, coagulograma, bilirrubinas totais e frações, TGO , TGP, fosfatase alcalina, sumário de urina, uréia e creatinina, eletroforese de proteínas plasmática, dosagem de cálcio, glicemia de jejum, ácido úrico, colesterol to tal e frações e triglicerídeos, radiografia do tórax e eletrocardiograma, todos dentro dos padrões normais. O VHS apresentou discreta elevação. Não foram realizadas a biópsia da mucosa retal ou a aspiração com agulha fina da gordura abdominal, nem a punção da medula óssea.

Em abril de 2000, nova videolaringoscopia foi feita, verificando-se ausência de lesão. Desde então, o paciente não apresentou recidivas. Diante dos resultados obtidos, chegou-se ao diagnóstico de amiloidose laríngea primária.

\section{DISCUSSÃO}

A amiloidose é uma doença rara, e que ainda permanece com etiologia desconhecida. Em 1956, Symmers classificou a amiloidose em: primária, localizada ou generalizada; secundária, localizada ou generalizada; associada com mieloma múltiplo; e hereditária ou familiar. Desde então, vem sofrendo algumas transformações do ponto de vista prático ${ }^{1,4}$.

Esta condição pode acometer diversos órgãos, mas raramente surge como um tumor do trato aerodigestivo; entretanto, a laringe é o local mais comumente acometido por estes depósitos ao nível da cabeça e pescoço ${ }^{1,6}$. O corre mais no sexo masculino que no feminino numa proporção de $3: 1^{1,6,7}$. A faixa etária acometida é variável, dos 8 aos 80 anos, sendo mais freqüente por volta da quarta à sexta décadas de vida. Não há preferência racial ${ }^{7}$.

A amiloidose laríngea é usualmente primária, de evolução lentamente progressiva, sendo incomum surgir como primeira manifestação de uma amiloidose sistêmica, tendo por isso em geral, bom prognóstico. Mesmo assim, diante de um caso de amiloidose laríngea, deve-se sempre afastar uma amiloidose secundária ou sistêmica. Há alguns relatos de possível transformação maligna da doença, mas sem confirmação científicå ${ }^{8}$.

Ainda não existe uma concordância quanto ao local da laringe mais comumente envolvido. Alguns autores acreditam ser as falsas cordas vocais e o ventrículo; outros citam as pregas vocais como principais sítios?. Contudo, qualquer local da laringe pode ser acometido podendo haver inclusive concomitância de lesões. Por isso, a doença pode se apresentar com sintomatologia variada. A rouquidão é na maioria das vezes o principal sintoma, mas dispnéia, disfagia, sensação de corpo estranho e até hemoptise podem estar presentes $1,3,4,6-8$

0 paciente com diagnóstico de amiloidose laríngea deverá ser submetido a uma avaliação geral para excluir uma forma secundária ou sistêmica da doença. A investigação clínica inclui o hemograma, coagulograma, VHS e outras provas de atividade inflamatória, pesquisa de fator reumatóide (pela possível associação com a artrite reumatóide), eletroforese de proteínas plasmáticas (para investigar mieloma múltiplo), testes de função hepática e renal, radiografia do tórax, eletrocardiograma e a ultrasonografia abdominal. A biópsia da mucosa retal ou das glândulas salivares, e a aspiração da gordura abdominal com agulha fina podem ser realizadas para afastar doença sistêmica. A punção da medula óssea é feita por alguns para excluir mieloma múltiplo ${ }^{1,3,3,7,7}$.

0 tratamento clínico da amiloidose laríngea com corticosteróides ou radioterapia tem sido ineficaz, sendo o tratamento cirúrgico o mais indicado ${ }^{2}$. A intervenção cirúrgica por via endoscópica tem sido a mais utilizada, mas técnicas mais radicais como as laringectomias parciais ou totais podem ser usadas sobretudo nos casos mais invasivos que produzem obstrução aérea ${ }^{1-9}$. A excisão da lesão com $\mathrm{CO} 2$ laser tem sido apontada como uma boa alternativa por produzir menos processos inflamatórios da mucosa e submucosa, e menos lesão que a técnica cirúrgica comum ${ }^{2,6,9}$. No entanto, em qualquer técnica utilizada poderá haver recidivas e novas excisões serem necessárias. Por isso, o paciente portador de amiloidose laríngea deverá ser mantido em seguimento.

\section{COMENTÁRIOSFINAIS}

Por ser a amiloidose laríngea uma doença pouco freqüente e pelo fato de não possuir sintomatologia e lesões características, esta enfermidade poderá muitas vezes passar despercebida, uma vez que para se fazer esse diagnóstico é preciso primeiramente haver a suspeita clínica, a qual deverá ser confirmada pelo estudo histopatológico com o vermelho de congo ou outros méto dos mais sofisticados que possam identificar os depósitos de amilóide no meio extracelular; a coloração com hematoxilina-eosina, usada na prática diária do anátomo-patologista, mostra-se de pouca valia para 0 diagnóstico da amiloidose.

O tratamento da amiloidose laríngea primária é essencialmente cirúrgico com exérese da lesão, sendo a terapêutica medicamentosa ineficaz. 0 paciente deverá ser mantido sob vigilância, com o intuito de diagnosticar precocemente recidivas e tratá-las adequadamente. Não foi relatado aqui o manejo nos outros tipos de amiloidose, restringindo-se apenas à amiloidose laríngea em sua forma primária.

\section{AGRADECIMENTOS}

Aos nossos pais, maridos e esposas, amigos e a todos que fazem parte do Serviço de Otorrinolaringologia da Santa Casa de Misericórida de Maceió. 


\section{REFERÊNCIASBIBUOGRÁFICAS}

1. Hellquist $\mathrm{H}$, Olofsson J, Sökjer $\mathrm{H}$ et al. Amyloidosis of the larynx. Acta Otolaryngol 1979; 88: 443-50.

2. Bennett JD et al. Primary amyloidosis of the larynx. The journal of laryngology and otology 1994; 108: 339-40.

3. Grammans K, Lubsen H. Clinical implications of laryngeal amyloidosis. The journal of laryngology and otology 1985; 99: 617-23.

4. Mitrani M, Biller HF. Laryngeal amyloidosis. Laryngoscope 1985; 95: $1346-7$.
5. Smith O, Irish J, Nostrand PV. Pathologic quiz case 1. Pathologic quis case 2. Arch Otolaryngol head neck surgery 1989; 115: 390-3.

6. Balbani AP, Formigoni GG, Sennes LV et al. Primary laryngeal amyloidosis in a child. The journal of otolaryngology 1999; 28 : 171-2.

7. Arrarte JL, Martins WM, Teló L et al. Amiloidose laríngea primária: relato de caso. Revista brasileira de otorrinolaringologia 1997; 63(2):152-6.

8. Koskas G, Ketari M, Renou G. Évolution néoplasique d'une amylose laryngée a propos d'un cas. Ann Oto-laryng (Paris) 1989; 106: 338-41.

9. Talbot AR. Laryngeal amyloidosis. The journal of laryngology and otology 1990; 104: 147-9. 